\title{
Presence of microsatellite lesions with colorectal liver metastases correlate with intrahepatic recurrence after surgical resection
}

\author{
HIROYUKI HAYASHI ${ }^{1,2}$, KAZUKI NABESHIMA ${ }^{1}$, MAKOTO HAMASAKI ${ }^{1}$, \\ YUICHI YAMASHITA ${ }^{2}$, TAKAYUKI SHIRAKUSA ${ }^{3}$ and HIROSHI IWASAKI ${ }^{1}$ \\ Departments of ${ }^{1}$ Pathology, ${ }^{2}$ Gastroenterological Surgery and ${ }^{3}$ Thoracic, Endocrine and Pediatric Surgery, \\ Fukuoka University Hospital and School of Medicine, 7-45-1 Nanakuma, Jonan-ku, Fukuoka 814-0180, Japan
}

Received November 19, 2008; Accepted December 22, 2008

DOI: 10.3892/or_00000262

\begin{abstract}
Hepatectomy is the treatment of choice for patients with resectable colorectal carcinoma metastases. However, recurrences occur in about half to two-thirds of the patients after surgery. To reduce the recurrence rate, it is important to isolate those factors that influence intrahepatic recurrence. In this study, we assessed histopathological factors associated with intrahepatic recurrences in 53 cases of liver metastases with special reference to microsatellite metastases. In 18 of the 53 cases, the entire resected liver tissue block was sectioned, processed into H\&E slides, and examined microscopically. For the 53 cases, 1-, 3-, and 5-year survival rates were $87.9,65.7$ and $46.1 \%$, respectively, with a median survival of 74 months. Univariate analysis showed a significant association of intrahepatic recurrence $(\mathrm{p}=0.039)$, intraor extrahepatic recurrence $(\mathrm{p}=0.003)$, and surgical margin status of $<1 \mathrm{~mm}(\mathrm{p}=0.013)$ with poor overall survival. Multivariate analysis showed that intra- or extrahepatic recurrence was an independent indicator of poor overall survival $(\mathrm{p}=0.034)$. In the fully examined 18 cases, intrahepatic recurrences were significantly associated with microsatellite metastases around the main metastatic tumors. Microsatellite metastases were detected in 10 cases $(55.5 \%)$ and showed a trend toward a worse overall survival. Moreover, all microsatellite lesions were found within $4 \mathrm{~mm}$ from the advancing margin of the main metastases, and most of them (7/10) were located within $2 \mathrm{~mm}$ of the tumor border. Collectively, a surgical margin of $1 \mathrm{~mm}$ at least is needed, however, a minimum surgical margin of $2 \mathrm{~mm}$ seems preferable based
\end{abstract}

Correspondence to: Professor Kazuki Nabeshima, Department of Pathology, Fukuoka University Hospital and School of Medicine, 7-45-1 Nanakuma, Jonan-ku, Fukuoka 814-0180, Japan

E-mail: kaznabes@fukuoka-u.ac.jp

Key words: colorectal cancer, liver metastases, microsatellite lesion, surgical margin status, prognosis on the distribution of intrahepatic recurrence-associated microsatellite lesions.

\section{Introduction}

Surgical resection of hepatic metastases from colorectal cancer is considered the treatment of choice. Adaptation of new surgical techniques and enhanced postoperative care has improved the surgical outcome. However, the incidence of recurrence at a median follow-up of 29 months was reported in one recent multicenter study to be $40 \%$ and the 5 -year survival rate was as high as $58 \%$ (1). Predictors of survival after resection include primary tumor-associated factors and those associated with metastatic lesions. The former include primary tumor stage, level of preoperative carcinoembryonic antigen (CEA), and presence of extrahepatic disease including presence of regional lymph node metastasis (2-5). The latter includes hepatic tumor size, number of hepatic metastases, margin status, and intrahepatic vascular or bile duct invasion by cancer cells (1-3,6-9). Fibrous capsule formation is also associated with a lower rate of initial local recurrence in the remnant liver (10).

The present retrospective study was designed to identify local factors that influence survival and local recurrence after surgical excision of liver metastases from primary colorectal cancers in order to improve surgical handling of hepatic colorectal metastases and thus improvement of prognosis. For this purpose, we examined resected liver tissues and analyzed potential histopathological factors that could influence intrahepatic recurrence after resection.

\section{Materials and methods}

Patients. We reviewed 53 cases of liver metastases from colorectal carcinomas that had been surgically resected at the Department of Gastroenterological Surgery, Fukuoka University Hospital between September 1993 and October 2006. Anonymous use of redundant tissue is part of the standard treatment agreement with patients in our hospital when no objection is expressed. The following parameters were retrieved from the medical records of each patient; age, sex, hepatic metastasis time (synchronous or metachronous), tumor distribution (unilobular or bilobular), number and size 

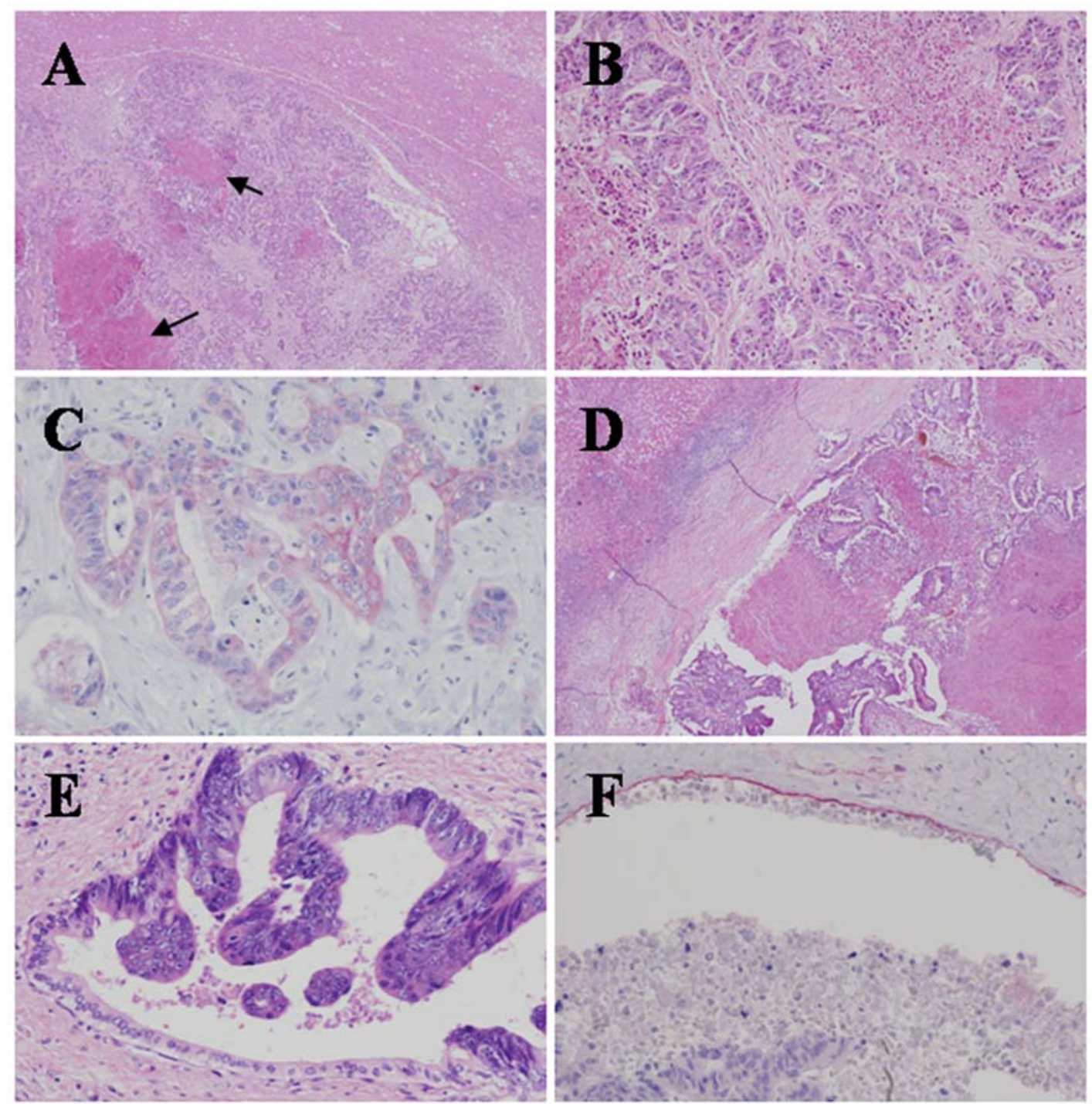

Figure 1. Histopathological findings of hepatic metastases from colorectal carcinoma. (A) A metastatic tumor in the liver with areas of necrosis (arrows). (B) Proliferation of carcinoma cells forming irregular fused tubular structures. (C) Metastatic carcinoma cells were frequently positive for CK20. (D) Fibrous capsule formation was noted around the metastatic tumor. (E) Carcinoma cells invaded the bile duct replacing the duct epithelium. (F) Portal invasion was demonstrated with CD34 immunostaining of the endothelium.

of tumors, intrahepatic bile duct involvement, capsule formation, width of resection margins, and intrahepatic and extrahepatic recurrences. The follow-up period ranged from 2-119 months (median, 27.9 months) after hepatectomy.

Pathologic evaluation. In 18 of the 53 cases, the whole surgically resected liver specimens were sectioned and processed into paraffin blocks for full histopathological examination. Tissue sections were cut $4-\mu \mathrm{m}$ thick and stained with hematoxylin and eosin (H\&E). In the other 35 cases, representative multiple blocks that included tumor nodules and resection margins were prepared.

For immunohistochemistry, 4- $\mu \mathrm{m}$ thick sections were mounted on MAS (Matsunami Adhesive Silane)-coated glass slides, deparaffinized, and heated in a microwave oven $(700 \mathrm{~W})$ for $10 \mathrm{~min}$ to expose antigens in $10 \mathrm{mM}$ Na-citrate buffer ( $\mathrm{pH}$ 6.0). The antibodies used in this study were those against CD34 (clone QBEnd10; dilution 1:50, Immunotech, Prague, Czech Republic), cytokeratin 20 (CK20) (clone
Ks20.8; dilution 1:50, Dako Cytomation, Glostrup, Denmark), and D2-40 (clone D2-40; dilution 1:100, Dako). Immunohistochemical staining was performed by the LSAB (Labeled streptavidin-biotin) method (Dako). Alkaline phosphatase or horseradish peroxidase activity was visualized by naphtholAS-BI-phosphate (Sigma, St. Louis, MO) or Metal-3,3'diaminobenzidine (Pierce, Rockford, IL) as a substrate, respectively. The immunohistochemical specificity of the antibodies was confirmed by two types of negative controls: substituting mouse nonimmune IgG for the primary antibodies and omitting the primary antibodies from the staining protocol.

Representative histological findings are shown in Fig. 1. Liver metastases from colorectal carcinoma frequently showed central necrosis (Fig. 1A) and consisted of proliferation of atypical columnar cells of an intestinal type forming fused tubular structures (Fig. 1B). Colorectal origin was supported by immunoreactivity to CK20 (Fig. 1C). The metastases occasionally formed fibrous capsules (Fig. 1D) and invaded 
Table I. Clinicopathological characteristics of patients and univariate analysis for survival $(n=53)$.

Factor $\quad$ No. $(\%) \frac{\text { Overall survival }}{1 \text { year 3 years } 5 \text { years }}$ P-value

Age (years)
$<65$

$<65$

$\geq 65$

$34(64.2) \quad 85.3$

$19(35.8) \quad 93.3$

85.3

40.6

$93.3 \quad 60.0$

0.232

Sex

Male

$$
31 \text { (58.5) }
$$

89.7

22 (48.5)

85.7

89.7

39.5

Female

Timing

of hepatic

metastasis

Synchronou

$16(30.2)$

81.3

$81.3 \quad 34.8$

Metachronous

37 (69.8)

91.0

$91.0 \quad 48.5$

0.897

Tumor

distribution

Unilobular

$41(77.4) \quad 84.4$

$84.4 \quad 43.4$

Bilobular

$12(22.6) \quad 100.0$

$100.0 \quad 68.6$

0.687

No. of tumors

1

$\geq 2$

$35(66.0) \quad 84.6$

$84.6 \quad 36.6$

$18(34.0) \quad 94.1 \quad 94.1 \quad 64.7$

0.367

Tumor size

$\leq 50 \mathrm{~mm}$

$45(84.9) \quad 88.2$

$88.2 \quad 49.9$

$>50 \mathrm{~mm}$

$8(15.1) \quad 85.8$

$85.8 \quad 25.8$

0.384

Capsule

formation

Absent

Present

$$
42(79.2) \quad 82.6
$$

$82.6 \quad 37.0$

$11(20.8) \quad 100.0 \quad 100.0 \quad 75.0$

0.107

Surgical

margin

$<1 \mathrm{~mm}$

$\geq 1 \mathrm{~mm}$

$11(28.3) \quad 70.7$

$\begin{array}{ll}70.7 & 39.2\end{array}$

$\begin{array}{llll}42(79.2) & 92.3 & 92.3 & 50.8\end{array}$

0.013

Intrahepatic

recurrence

$\begin{array}{llllll}\text { Absent } & 34(64.2) & 78.9 & 48.3 & 18.1 & \\ \text { Present } & 19(35.8) & 93.7 & 79.4 & 68.0 & 0.039\end{array}$

Intra- or

extrahepatic

recurrence

\begin{tabular}{llllll} 
Absent & $19(35.8)$ & 94.7 & 94.7 & 94.7 & \\
Present & $34(64.2)$ & 84.6 & 52.9 & 22.5 & 0.003 \\
\hline
\end{tabular}

bile ducts (Fig. 1E) and portal veins (Fig. 1F). The latter was detected by use of CD34 immunostaining.
Statistical analysis. Associations between microsatellite metastases and several clinicopathological parameters were evaluated using the $\chi^{2}$ test or Fisher's exact test. Survival curves were plotted using the Kaplan-Meier method, and p-values were calculated using the log-rank test. Multivariate analysis was performed by Cox's proportional hazards regression analysis. A p-value of $<0.05$ denoted the presence of statistically significant difference. All statistical evaluations were performed using the SPSS II (SPSS Japan Inc., Tokyo, Japan) software package.

\section{Results}

Clinicopathological characteristics. Table I presents the clinicopathological characteristics of 53 patients included in this study. The median age was 60 years (range, 33-80). The primary tumor originated from the colon in $31(58.5 \%)$ cases, the rectum in $19(35.8 \%)$ cases, and both colon and rectum in $3(5.7 \%)$ cases. The median number of metastases was 1.74 (range, 1-7), and $35(66.0 \%)$ cases had one liver metastatic lesion, while 18 (34.0\%) had more than 2 metastases. The median diameter of the metastatic lesion was $36 \mathrm{~mm}$ (range, $5-100 \mathrm{~mm}$ ), and $<50 \mathrm{~mm}$ in 45 (84.9\%) cases, but $>50 \mathrm{~mm}$ in $8(15.1 \%)$. The median width of the margin was $6.6 \mathrm{~mm}$ (range, $0.5-75 \mathrm{~mm}$ ). In $11(28.3 \%)$ cases, the margin was $<1 \mathrm{~mm}$, and $>1 \mathrm{~mm}$ in $42(79.2 \%)$. Intra-hepatic bile duct involvement was detected in only 2 (3.8\%) cases (data not shown). Intra- or extrahepatic recurrence, extrahepatic recurrence, or intrahepatic recurrence after liver resection for colorectal liver metastases was detected in 34 (64.2\%), $25(47.2 \%)$, and $19(35.8 \%)$ cases, respectively.

Factors influencing overall survival. First, we evaluated the associations between clinicopathological variables and overall survival. The median survival time was 51.2 months. The 1,3-, and 5-year survival rates were 87.9, 65.7, and $46.1 \%$, respectively (Fig. 2A). Univariate analysis showed significant associations of intra-or-extrahepatic recurrence $(\mathrm{p}=0.003)$, intrahepatic recurrence $(\mathrm{p}=0.039)$, and surgical margin $<1 \mathrm{~mm}(\mathrm{p}=0.013)$ with poor overall survival (Table I). The log-rank test also showed significant associations of intra-or-extrahepatic recurrence, surgical margin $<1 \mathrm{~mm}$, and intrahepatic recurrence with poor overall survival (Fig. 2B-D). Multivariate analysis identified intra-or-extrahepatic recurrence as an independent predictor of poor survival (Table II).

Intrahepatic recurrence and microsatellite metastases. Next, we investigated the pathological features that were closely associated with intrahepatic recurrence because the latter was the target that could be reduced through improvement of surgical procedures. For this purpose, we examined 18 cases with metastases in whom sections of the whole resected liver tissues were available for examination. Intrahepatic recurrence after hepatectomy was significantly associated with the presence of microsatellite metastases (Table III). Microsatellite metastases were defined as minute islands of metastatic lesions that were found around the main colorectal liver metastases without any evidence of histopathological continuity (Fig. 3) and were confirmed by CK20 immuno- 
$\mathbf{A}$

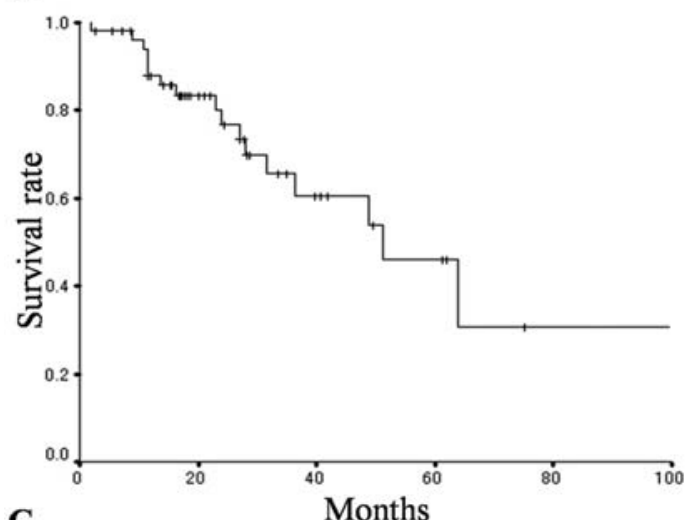

C

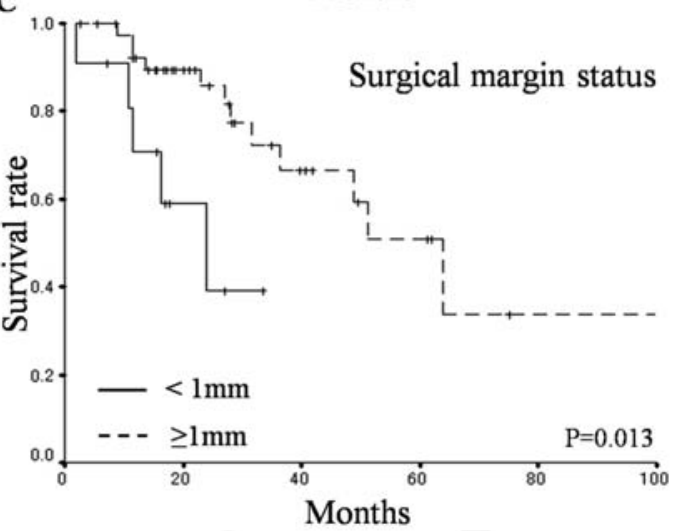

B

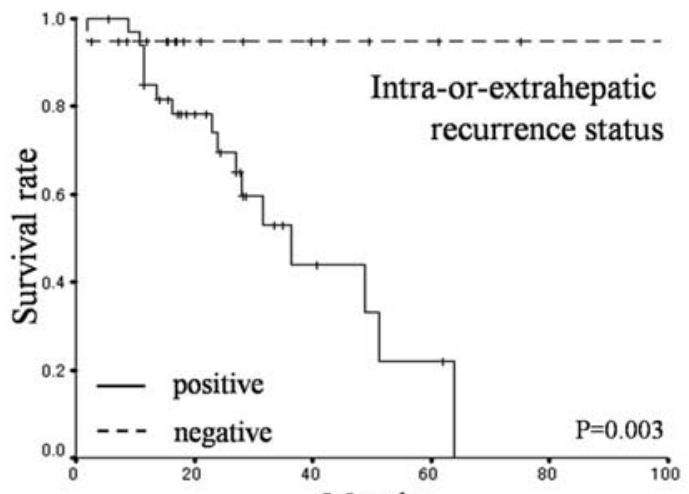

D

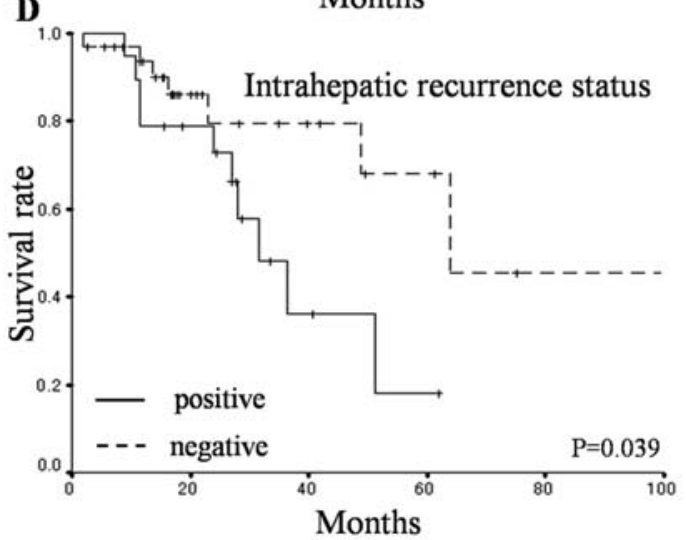

Figure 2. Overall survival rates. (A) Overall survival rates for 53 patients after resection of liver metastases from colorectal carcinoma. The 1-, 3-, and 5-year survival rates were $87.9,65.7$, and $46.1 \%$, respectively. Survival curves according to the status of (B) intra- or extrahepatic recurrence, (C) surgical margin, and (D) intrahepatic recurrence. The 5-year survival rates of patients without recurrences or with surgical margin of $\geq 1$ mm were significantly higher than those of patients with recurrences or with surgical margin of $<1 \mathrm{~mm}$, respectively $(\log$-rank test, $\mathrm{B}, \mathrm{p}=0.003 ; \mathrm{C}, \mathrm{p}=0.013 ; \mathrm{D}, \mathrm{p}=0.039)$.

Table II. Multivariate analysis of survival.

\begin{tabular}{lccc}
\hline Factor & Hazard ratio & $\begin{array}{c}95 \% \text { Confidence } \\
\text { interval }\end{array}$ & P-value \\
\hline $\begin{array}{l}\text { Intra-or-extra- } \\
\text { hepatic recurrence }\end{array}$ & 10.03 & $1.19-84.54$ & 0.034 \\
$\begin{array}{l}\text { Surgical margin } \\
\text { status: <1 mm }\end{array}$ & 3.01 & $0.96-9.39$ & 0.057 \\
$\begin{array}{l}\text { Intrahepatic } \\
\text { recurrence }\end{array}$ & 1.13 & $0.38-3.34$ & 0.823 \\
\hline
\end{tabular}

reactivity. Microsatellite lesions were detected in 10 of the $18(55.5 \%)$ cases, with a median number of 1.5 (range, 1-4) per case. The distance between microsatellite lesions and the main metastatic tumor is shown in Fig. 4. Microsatellite lesions were found within $4 \mathrm{~mm}$ from the main metastatic lesion, and 7 of them (70\%) were detected within $2 \mathrm{~mm}$. Microsatellite lesions were located evenly around the main metastatic tumors, and half of them were found at the surgical margin side of the main metastatic tumor. The presence of microsatellite lesions did not correlate with tumor size, number of tumors, or tumor distribution (Table IV). The presence of microsatellite lesions showed a trend toward a poorer overall survival, although the follow-up period is relatively short (Fig. 5).

\section{Discussion}

Hepatic resection is to date the most effective and only potentially curative therapy for hepatic colorectal metastasis, and 5-year survival rates of $25-58 \%$ have been reported (1,11-16). However, approximately a half to two-thirds of the patients experience recurrences $(1,2,17,18)$. The aim of the present study was to investigate the histopathological changes in and around hepatic colorectal metastases that were closely associated with intrahepatic recurrence. For this purpose, we thoroughly examined 18 resected liver tissues by sectioning and processing the entire resected liver tissue blocks, and found that intrahepatic recurrence after hepatectomy was significantly associated with the presence of microsatellite lesions around the main metastatic tumor. The microsatellite metastases were distributed within $4 \mathrm{~mm}$ from the advancing edges of the main tumors, although $50 \%$ and $70 \%$ of them were found within $1 \mathrm{~mm}$ and $2 \mathrm{~mm}$, respectively. Moreover, the microsatellite metastases were found in 10 of $18(55.6 \%)$ cases that underwent all-sections examination, while they were found only in 2 of $35(5.7 \%)$ cases that underwent ordinary multiple representative tissue sectioning for diagnosis. To our knowledge, our study is the 

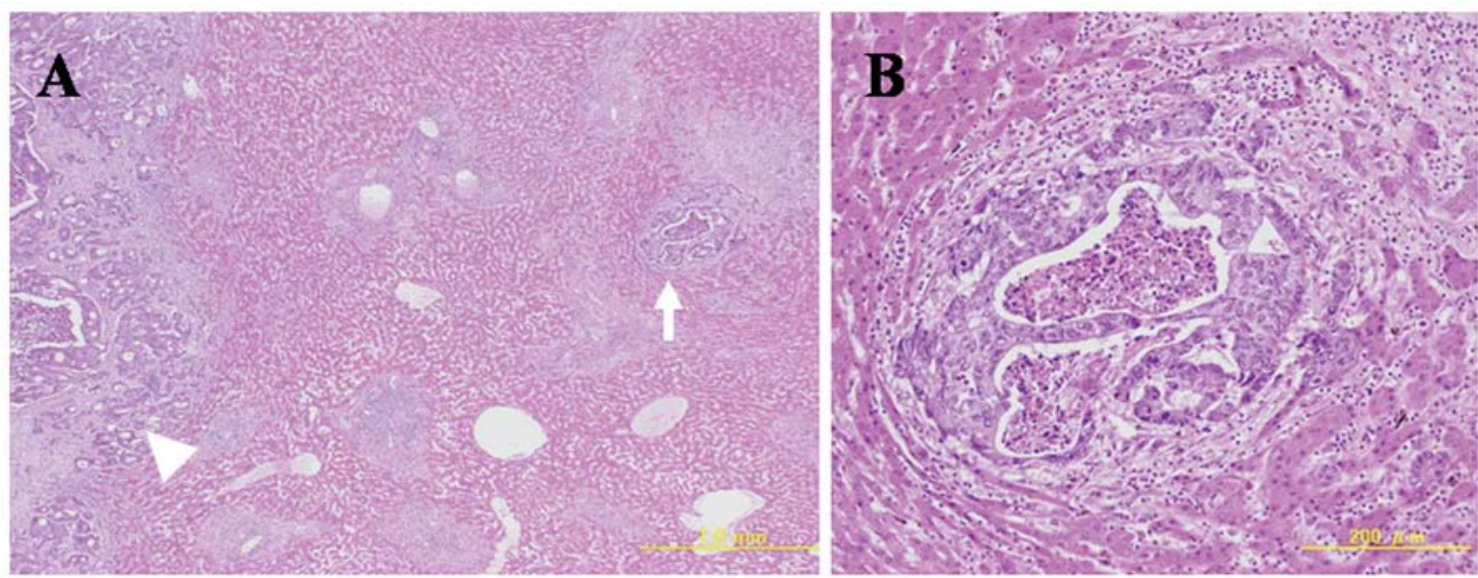

Figure 3. Microsatellite lesions of colorectal liver metastases. (A) A microsatellite lesion is a small metastatic nodule (arrow) which is not connected to the main colorectal metastasis (arrowhead) as evident by the presence of separating hepatic parenchyma. (B) A microsatellite lesion consisted of an island of carcinoma cells forming irregular fused tubular structures, accompanied by necrosis and mild chronic inflammatory infiltrates. (A) and (B), H\&E.

Table III. Correlation between intrahepatic recurrence and clinicopathological characteristics of colorectal metastases.

\begin{tabular}{|c|c|c|c|}
\hline \multirow[t]{2}{*}{ Factor } & \multicolumn{2}{|c|}{ Intrahepatic recurrence } & \multirow[t]{2}{*}{ P-value } \\
\hline & Present & Absent & \\
\hline \multirow{2}{*}{\multicolumn{4}{|c|}{$\begin{array}{l}\text { Microsatellite } \\
\text { lesions }\end{array}$}} \\
\hline & & & \\
\hline Present & $6(33.3)$ & $4(22.2)$ & 0.013 \\
\hline Absent & $0(0)$ & $8(44.4)$ & \\
\hline \multirow{2}{*}{\multicolumn{4}{|c|}{$\begin{array}{l}\text { Extrahepatic } \\
\text { recurrence }\end{array}$}} \\
\hline & & & \\
\hline Present & $5(27.8)$ & $4(22.2)$ & 0.131 \\
\hline Absent & $1(5.6)$ & $8(44.4)$ & \\
\hline \multicolumn{4}{|c|}{ No. of tumors } \\
\hline 1 & $3(16.7)$ & $1(5.6)$ & 0.083 \\
\hline$\geq 2$ & $3(16.7)$ & $11(61.1)$ & \\
\hline \multicolumn{4}{|l|}{ Tumor size } \\
\hline$\leq 40 \mathrm{~mm}$ & $2(11.1)$ & $1(5.6)$ & 0.245 \\
\hline$>40 \mathrm{~mm}$ & $4(22.2)$ & $11(61.1)$ & \\
\hline \multicolumn{4}{|c|}{ Tumor distribution } \\
\hline Unilobular & $2(11.1)$ & $1(5.6)$ & 0.245 \\
\hline Bilobular & $4(22.2)$ & $11(61.1)$ & \\
\hline \multicolumn{4}{|c|}{ Capsule formation } \\
\hline Present & $0(0)$ & $2(11.1)$ & 0.529 \\
\hline Absent & $6(33.3)$ & $10(55.6)$ & \\
\hline \multicolumn{4}{|c|}{ Surgical margin } \\
\hline$<1 \mathrm{~mm}$ & $1(5.6)$ & $4(22.2)$ & 0.615 \\
\hline$\geq 1 \mathrm{~mm}$ & $5(27.8)$ & $8(44.4)$ & \\
\hline \multicolumn{4}{|c|}{ Vascular involvement } \\
\hline Present & $0(0)$ & $4(22.2)$ & 0.245 \\
\hline Absent & $6(33.3)$ & $8(44.4)$ & \\
\hline
\end{tabular}

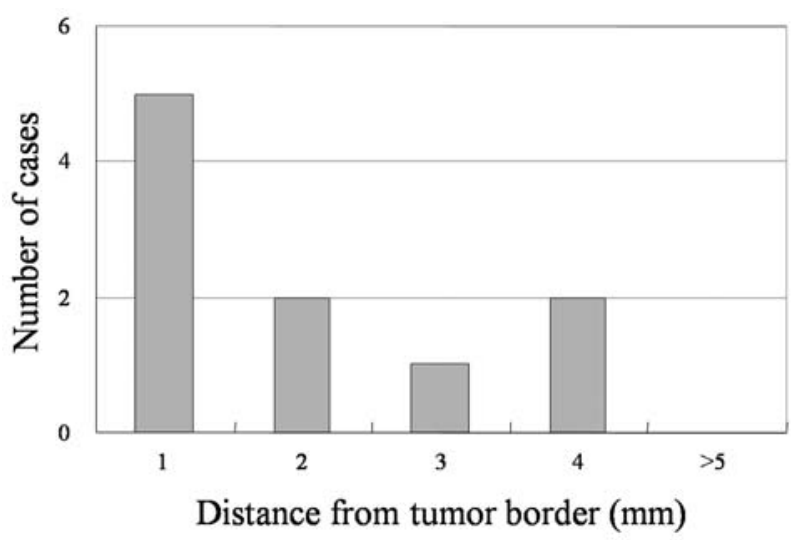

Figure 4. Distribution of microsatellite lesions detected by histological examination of resected hepatic tissues. In 18 cases, resected hepatic tissues were all sectioned, processed into H\&E slides, and examined microscopically. Microsatellite lesions were found in 10 cases $(55.5 \%)$, and all were found within $4 \mathrm{~mm}$ of the tumor border.

first to examine microsatellite metastases by full-sectioning of resected tissues. Since intrahepatic recurrence correlated with a shorter overall survival (Table I; Fig. 2D) and presence of microsatellite lesions also showed a trend towards poor survival (Fig. 5), control of microsatellite lesions by wider resection of the liver metastasis from colorectal cancer may improve survival after resection.

With regard to microsatellite lesions, Kokudo et al (8) found these lesions in the liver parenchyma surrounding colorectal metastases in $2.0 \%$ (4/199) of tested samples by genetic techniques, which were located within $4 \mathrm{~mm}$ of the tumor border. They also found histological micrometastases in $24.2 \%$ of the cases, all of which were found within $5 \mathrm{~mm}$ of the tumor border. Yokoyama et al (19) examined resected liver tissues by immunohistochemistry using anti-CK20 antibody and found micrometastases in $69.6 \%$ of curative hepatic resection for colorectal liver metastases. In their study, the presence of micrometastases predicted increased likelihood of intrahepatic recurrence and poor prognosis. Our results are 
Table IV. Correlation between microsatellite lesions and clinicopathological characteristics of colorectal metastases.

\begin{tabular}{|c|c|c|c|}
\hline \multirow[t]{2}{*}{ Factor } & \multicolumn{2}{|c|}{ Microsatellite lesions } & \multirow[t]{2}{*}{ P-value } \\
\hline & Present & Absent & \\
\hline \multicolumn{4}{|l|}{$\begin{array}{l}\text { Intrahepatic } \\
\text { recurrence }\end{array}$} \\
\hline Present & $6(33.3)$ & $0(0)$ & 0.013 \\
\hline Absent & $4(22.2)$ & $8(44.4)$ & \\
\hline \multicolumn{4}{|l|}{$\begin{array}{l}\text { Extrahepatic } \\
\text { recurrence }\end{array}$} \\
\hline Present & $7(38.9)$ & $2(11.1)$ & 0.153 \\
\hline Absent & $3(16.7)$ & $6(33.3)$ & \\
\hline \multicolumn{4}{|c|}{ No. of tumors } \\
\hline 1 & 7 (38.9) & $7(38.9)$ & 0.588 \\
\hline$\geq 2$ & $3(16.7)$ & $1(5.6)$ & \\
\hline \multicolumn{4}{|l|}{ Tumor size } \\
\hline$\leq 40 \mathrm{~mm}$ & $8(44.4)$ & $7(38.9)$ & 1.000 \\
\hline$>40 \mathrm{~mm}$ & $2(11.1)$ & $1(5.6)$ & \\
\hline \multicolumn{4}{|c|}{ Tumor distribution } \\
\hline Unilobular & $8(44.4)$ & 7 (38.9) & 1.000 \\
\hline Bilobular & $2(11.1)$ & $1(5.6)$ & \\
\hline \multicolumn{4}{|c|}{ Vascular involvement } \\
\hline Present & $2(11.1)$ & $2(11.1)$ & 1.000 \\
\hline Absent & $8(44.4)$ & $6(33.3)$ & \\
\hline
\end{tabular}

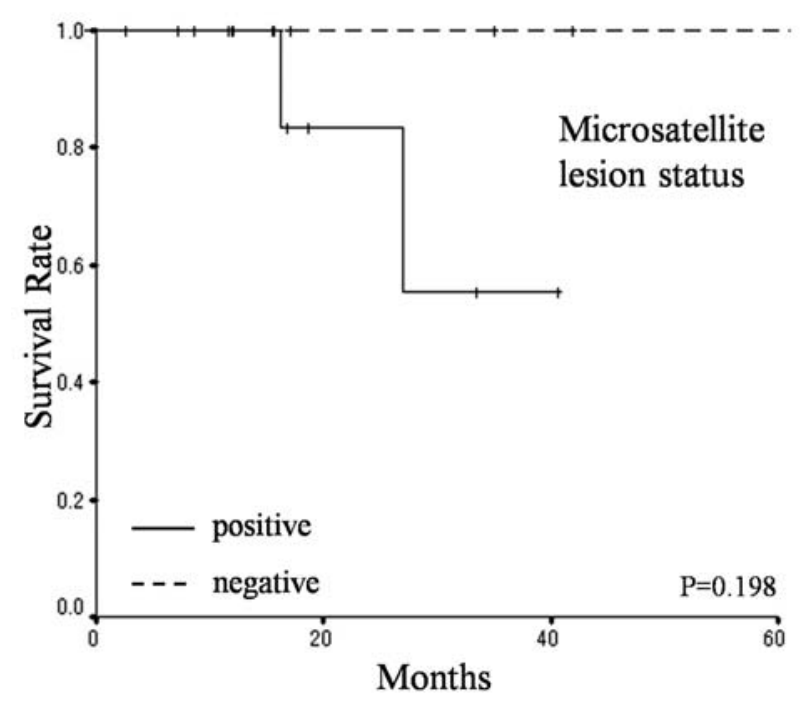

Figure 5. Overall survival curves according to the status of microsatellite metastases. The 3-year survival rate of patients without microsatellite metastases tended to be significantly higher than those of patients with microsatellite metastases (log-rank test, $\mathrm{p}=0.198)$.

in agreement with the above two reports. The presence of microsatellite metastases may be an indicator of widespread hepatic involvement by primary tumors (19). Alternatively, the biological nature of metastatic tumors may be considerably different from that of the primary colorectal cancer (20). Alterations of microenvironment of the normal liver parenchyma adjacent to the main colorectal metastasis, which are caused by host-tumor interactions, such as inflammatory reaction, angiogenesis or alteration of extracellular matrix, may assist small clusters of cancer cells detached from the main tumor to lodge and subsequently proliferate. In the present study, microsatellite lesions were frequently accompanied by mild to moderate chronic inflammatory infiltrates, as reported previously (21), although we do not know whether this inflammatory reaction promoted or halted development of microsatellite lesions in our cases. Elucidation of the mechanisms of alterations in the microenvironment that influence the development of microsatellite metastases may allow the control of intrahepatic recurrence after hepatic resection.

The size of the surgical margin is another factor that can influence recurrence and survival after resection of hepatic colorectal metastases $(1,7,8)$. Many surgeons try to achieve surgical margins as wide as safely possible during hepatic resection for colorectal metastases, but there is no conclusive evidence of safe negative margin width necessary for minimal recurrence and longer survival $(1,8)$. Cady et al $(7)$ used univariate analysis to conclude that a surgical margin $<10 \mathrm{~mm}$ was associated with a significantly shorter diseasefree survival. However, Altendorf-Hofmann and Scheele (22) reported that the actual width of the surgical margin had no effect on survival as long as the margin was negative. Others also reported that the outcome of patients with surgical margins $>1 \mathrm{~mm}$ but $<10 \mathrm{~mm}$ was comparable to that of patients with surgical margins wider than $10 \mathrm{~mm}(23,24)$. More recently, Pawlik et al (1) concluded that survival and recurrence risk were not influenced by the width of a negative surgical margin. The findings of previous reports $(8,17,18,25)$ added support to the above conclusion. Moreover, surgical margins wider than $10 \mathrm{~mm}$ are not always achievable because of the number or location of metastases, and the achievable rates were reported to be around 30-40\% in many institutions $(7,8)$. These lines of evidence support the concept of a limited negative margin resection in patients with hepatic colorectal metastases when unavoidable due to anatomical factors (e.g., number, location) of metastases. In the present study, our results on the surgical margin also supported this practical approach: surgical margin $<1 \mathrm{~mm}$ was associated with a shorter survival (Table I, Fig. 2C), while the width of a negative surgical margin did not significantly affect overall survival (data not shown). However, based on our findings that most $(70 \%)$ of intrahepatic recurrenceassociated microsatellite metastases were located within $2 \mathrm{~mm}$ of the main tumor border, a minimum surgical margin of $2 \mathrm{~mm}$ seems preferable. Although a surgical margin of at least $1 \mathrm{~mm}$ is also a choice, a margin of $1 \mathrm{~mm}$ may be too narrow for clinical use as suggested previously when considering measurement errors associated with a macroscopic surgical margin (8). Our findings add support to the proposal by Kokudo et al (8) for a surgical margin of $2 \mathrm{~mm}$ as a clinically acceptable minimum requirement. They reported that this minimum margin carries approximately a $6 \%$ risk of margin-related recurrence. 
In conclusion, thorough examination of fully-sectioned resected liver tissues showed a close association between microsatellite lesions and intrahepatic recurrence. Based on the distribution of the microsatellite lesions, we recommend a minimum surgical margin of $2 \mathrm{~mm}$.

\section{References}

1. Pawlik TM, Scoggins CR, Zorzi D, Abdalla EK, Andres A, Eng C, Curley SA, Loyer EM, Muratore A, Mentha G, Capussotti L and Vauthey JN: Effect of surgical margin status on survival and site of recurrence after hepatic resection for colorectal metastases. Ann Surg 241: 715-722, 2005.

2. Nordlinger B, Guiguet M, Vaillant JC, Balladur P, Boudjema K, Bachellier P and Jaeck D: Surgical resection of colorectal carcinoma metastases to the liver: a prognostic scoring system to improve case selection, based on 1568 patients. Association Francaise de Chirurgie. Cancer 77: 1254-1262, 1996.

3. Fong Y, Fortner J, Sun RL, Brennan MF and Blumgart LH: Clinical score for predicting recurrence after hepatic resection for metastatic colorectal cancer: analysis of 1001 consecutive cases. Ann Surg 230: 309-321, 1999.

4. Minagawa M, Makuuchi M, Torzilli G, Takayama T, Kawasaki S, Kosuge $\mathrm{T}$, Yamamoto $\mathrm{J}$ and Imamura $\mathrm{H}$ : Extension of the frontiers of surgical indications in the treatment of liver metastases from colorectal cancer: long-term results. Ann Surg 231: 487-499, 2000.

5. Radespiel-Troger M, Hohenberger $\mathrm{W}$ and Reingruber $\mathrm{B}$ : Improved prediction of recurrence after curative resection of colon carcinoma using tree-based risk stratification. Cancer 100: 958-967, 2004

6. Yamamoto J, Sugihara K, Kosuge T, Takayama T, Shimada K, Yamasaki S, Sakamoto M and Hirohashi S: Pathologic support for limited hepatectomy in the treatment of liver metastases from colorectal cancer. Ann Surg 221: 74-78, 1995.

7. Cady B, Jenkins RL, Steele GD Jr, Lewis WD, Stone MD, McDermott WV, Jessup JM, Bothe A, Lalor P, Lovett EJ, Lavin P and Linehan DC: Surgical margin in hepatic resection for colorectal metastasis: a critical and improvable determinant of outcome. Ann Surg 227: 566-571, 1998.

8. Kokudo N, Miki Y, Sugai S, Yanagisawa A, Kato Y, Sakamoto Y, Yamamoto J, Yamaguchi T, Muto T and Makuuchi M: Genetic and histological assessment of surgical margins in resected liver metastases from colorectal carcinoma: minimum surgical margins for successful resection. Arch Surg 137: 833-840, 2002.

9. Adam R, Delvart V, Pascal G, Valeanu A, Castaing D, Azoulay D, Giacchetti S, Paule B, Kunstlinger F, Ghemard O, Levi $\mathrm{F}$ and Bismuth $\mathrm{H}$ : Rescue surgery for unresectable colorectal liver metastases downstaged by chemotherapy: a model to predict long-term survival. Ann Surg 240: 644-657, 2004.

10. Lunevicius R, Nakanishi H, Ito S, Kozaki K, Kato T, Tatematsu $\mathrm{M}$ and Yasui K: Clinicopathological significance of fibrotic capsule formation around liver metastasis from colorectal cancer. J Cancer Res Clin Oncol 127: 193-199, 2001 .
11. Adson MA, van Heerden JA, Adson MH, Wagner JS and Ilstrup DM: Resection of hepatic metastases from colorectal cancer. Arch Surg 119: 647-651, 1984.

12. Hughes KS, Rosenstein RB, Songhorabodi S, et al: Resection of the liver for colorectal carcinoma metastases. A multiinstitutional study of long-term survivors. Dis Colon Rectum 31: 1-4, 1988.

13. Scheele J, Stang R, Altendorf-Hofmann A and Paul M: Resection of colorectal liver metastases. World J Surg 19: 59-71, 1995.

14. Adam R, Avisar E, Ariche A, Giachetti S, Azoulay D, Castaing D, Kunstlinger F, Levi F and Bismuth F: Five-year survival following hepatic resection after neoadjuvant therapy for non-resectable colorectal. Ann Surg Oncol 8: 347-353, 2001.

15. Choti MA, Sitzmann JV, Tiburi MF, Sumetchotimetha W, Rangsin R, Schulick RD, Lillemoe KD, Yeo CJ and Cameron JL: Trends in long-term survival following liver resection for hepatic colorectal metastases. Ann Surg 235: 759-766, 2002.

16. Abdalla EK, Vauthey JN, Ellis LM, Ellis V, Pollock R, Broglio KR, Hess K and Curley SA: Recurrence and outcomes following hepatic resection, radiofrequency ablation, and combined resection/ ablation for colorectal liver metastases. Ann Surg 239: 818-825, 2004.

17. Bozzetti F, Doci R, Bignami P, Morabito A and Gennari L: Patterns of failure following surgical resection of colorectal cancer liver metastases. Rationale for a multimodal approach. Ann Surg 205: 264-270, 1987.

18. Harned R II, Chezmar JL and Nelson RC: Recurrent tumor after resection of hepatic metastases from colorectal carcinoma: location and time of discovery as determined by CT. AJR Am J Roentgenol 163: 93-97, 1994.

19. Yokoyama N, Shirai Y, Ajioka Y, Nagakura S, Suda T and Hatakeyama K: Immunohistochemically detected hepatic micrometastases predict a high risk of intrahepatic recurrence after resection of colorectal carcinoma liver metastases. Cancer 94: 1642-1647, 2002.

20. Bird NC, Mangnall D and Majeed AW: Biology of colorectal liver metastases: a review. J Surg Oncol 94: 68-80, 2006.

21. Okano K, Maeba T, Moroguchi A, Ishimura K, Karasawa Y, Izuishi K, Goda F, Usuki H, Wakabayashi $\mathrm{H}$ and Maeta $\mathrm{H}$ : Lymphocytic infiltration surrounding liver metastases from colorectal cancer. J Surg Oncol 82: 28-33, 2003.

22. Altendorf-Hofmann A and Scheele J: A critical review of the major indicators of prognosis after resection of hepatic metastases from colorectal carcinoma. Surg Oncol Clin North Am 12: 165-192, 2003.

23. Gayowski TJ, Iwatsuki S, Madariaga JR, Selby R, Todo S, Irish W and Starzl TE: Experience in hepatic resection for metastatic colorectal cancer: analysis of clinical and pathologic risk factors. Surgery 116: 701-710, 1994.

24. Ohlsson B, Stenram U and Tranberg KG: Resection of colorectal liver metastases: 25-year experience. World J Surg 22: 267-276, 1998.

25. Ekberg H, Tranberg KG, Andersson R, Lundstedt C, Hagerstrand I, Ranstam J and Bengmark S: Pattern of recurrence in liver resection for colorectal secondaries. World J Surg 11: 541-547, 1987. 